\title{
Vibration analysis of rotating tapered Timoshenko beams by a new finite element model
}

\author{
Bulent Yardimoglu \\ Department of Mechanical Engineering, Izmir Institute of Technology, 35430, Urla, Izmir, Turkey \\ Tel.: +90 232750 6599; E-mail: bulentyardimoglu@iyte.edu.tr
}

Received 5 August 2005

Revised 7 October 2005

\begin{abstract}
A new finite element model is developed and subsequently used for transverse vibrations of tapered Timoshenko beams with rectangular cross-section. The displacement functions of the finite element are derived from the coupled displacement field (the polynomial coefficients of transverse displacement and cross-sectional rotation are coupled through consideration of the differential equations of equilibrium) approach by considering the tapering functions of breadth and depth of the beam. This procedure reduces the number of nodal variables. The new model can also be used for uniform beams. The stiffness and mass matrices of the finite element model are expressed by using the energy equations. To confirm the accuracy, efficiency, and versatility of the new model, a semi-symbolic computer program in MATLAB ${ }^{\circledR}$ is developed. As illustrative examples, the bending natural frequencies of non-rotating/rotating uniform and tapered Timoshenko beams are obtained and compared with previously published results and the results obtained from the finite element models of solids created in ABAQUS. Excellent agreement is found between the results of new finite element model and the other results.
\end{abstract}

\section{Introduction}

It is well known that when the beams are stubby or when the higher modes are of interest in bending vibrations, Timoshenko beam theory is employed. The effects of shear deformation and rotary inertia are taken into account in this theory which is expressed by two coupled partial differential equations. For free vibration of uniform beams, the coupled equations can be reduced to one single equation since the coefficients appeared in this set of equations are constants. However, for tapered beams, the aforementioned coefficients are variables. On the other hand, consideration of the rotational effects on the beam vibrations causes addition of a term with variable coefficient in those equations. Due to the variable coefficients, it is in general difficult to obtain exact solutions of vibration problems of rotating Timoshenko beams with varying cross-section. Therefore, selecting a number of cross-section variation functions, the problem has been solved mainly by numerical or approximate methods. A carefully selected sample of the relevant literature is as follows:

Exact solution for the vibration of simply supported uniform Timoshenko beam can be found in some textbooks on vibration such as reference [9]. Huang [7] presented frequency and normal mode equations for flexural vibrations of uniform Timoshenko beams with six common boundary conditions.

Davis et al. [4] derived a Timoshenko beam finite element model having two nodes of two degrees of freedoms consisting of transverse displacement and cross-sectional rotation by solving the static equilibrium equations of an infinitesimal unloaded element. Dawe [5] presented a three-noded Timoshenko beam element based on the coupled displacement field; the lateral deflection function is linked to the cross-sectional rotation function by satisfying the unloaded and homogeneous form of the coupled differential equations. Nodal freedoms of the latter are the same 
as the first. Alternatively, Thomas et al. [19] presented a Timoshenko beam element having six degrees of freedom, comprising the transverse displacement, the cross-sectional rotation, and the shear deformation at the element ends. In order to analyze the in-plane (lead-lag) and out-of-plane (flapping) vibration characteristics of the rotating uniform Timoshenko beams, Yokoyama [22] developed a two-noded finite element model by means of a statical moment-shear equilibrium condition and the relation between cross-sectional rotation and shear deformation; the nodal freedoms are the transverse displacement assumed as a cubic displacement distribution and the cross-sectional rotation.

A number of papers for vibration analysis of tapered Timoshenko beams by finite element method have been published. To [20] used the finite element model given by Thomas et al. [19] for vibration analysis of a linearly tapered Timoshenko beam. Bazoune and Khulief [1] referred to Yokoyama [22] and Przemieniecki [17] for elemental shape functions in their study on vibration of rotating linearly tapered Timoshenko beams. Likewise, Mulmule et al. [14] employed the shape function given by Yokoyama [22] for flexural vibration of rotating linearly tapered Timoshenko beams. Rao and Gupta [18] derived the element mass and stiffness matrices for a rotating twisted and tapered Timoshenko beam element by considering bending deflection, shear deflection, bending slope, and shear slope as nodal freedoms. The displacements functions for bending and shear are assumed to be polynomials of third degree. However, cross-sectional tapering functions are not taken into account in the derivation of the finite element displacement or shape functions used in the aforementioned models, while they are considered as geometrical properties in energy integrals. Cleghorn and Tabarrok [3] developed a two-noded finite element formulation for a tapered Timoshenko beam for free lateral vibration analysis. In their model, the shape functions are obtained from the homogeneous solution of the governing equations for static deflection. They judged that the inclusion of the shear strain in nodal variables as in model used by To [20] is superfluous, and then selected the lateral displacement and rotation of cross-section as the nodal variables. One of the drawbacks of this model is the tapering function based on the cross-sectional area. Another one is the removable singularity for the case of a uniform beam. For the latter, Cleghorn and Tabarrok [3] used the modifications by replacing the logarithmic terms with Taylor series in powers of singularity parameter. However, in general, the variation of the cross sections of the beams is defined by using their breadth and/or depth not by cross-sectional area. On the other hand, the usage of series expansions can cause to lose the accuracy of the results.

The vibration problems of tapered Timoshenko beams have been also studied by other methods such as the modified differential quadrature method [2], the dynamic discretization technique [6], the spline interpolation technique [10], the transfer matrix method [11], and the method of Frobenius [12]. Among these studies, Lee and Lin [12] shown that if the coefficient of the reduced differential equation are in polynomial form, then the exact fundamental solutions can be obtained.

From the foregoing discussion on the finite element formulation, it is apparent that there is no available shape functions incorporated with the taper parameter(s) based on the breadth and/or depth of the cross-section of the tapered beam. Therefore, the main purpose of this paper is to propose the novel finite element model based on the coupled displacement field incorporating the taper functions of breadth and depth of the rectangular cross-sectioned Timoshenko beams. The new finite element model derived in this study has exact stiffness matrix, but approximate mass matrix due to the usage of static equilibrium condition as in references [4,5]. It is clear that the usage of the approximate mass matrix requires an increase in the number of elements required for a desired accuracy. However, this is amply compensated by the simplicity of the mathematical analysis it provides [16]. Finally, the new model is verified for out-of-plane vibration of non-rotating/rotating uniform and tapered Timoshenko beams by comparisons of the results obtained from the semi-symbolic code of the present model developed in MATLAB ${ }^{\circledR}$ with the results available in the literature and results obtained from the solid models in ABAQUS, respectively. The all results are given in tabular form to show the accuracy of the present new model clearly.

\section{Derivation of the finite element displacement functions}

The coupled partial differential equations of motion for a Timoshenko beam with variable cross-section are given in references $[15,16]$. The homogeneous form of these equations are written as follows: 


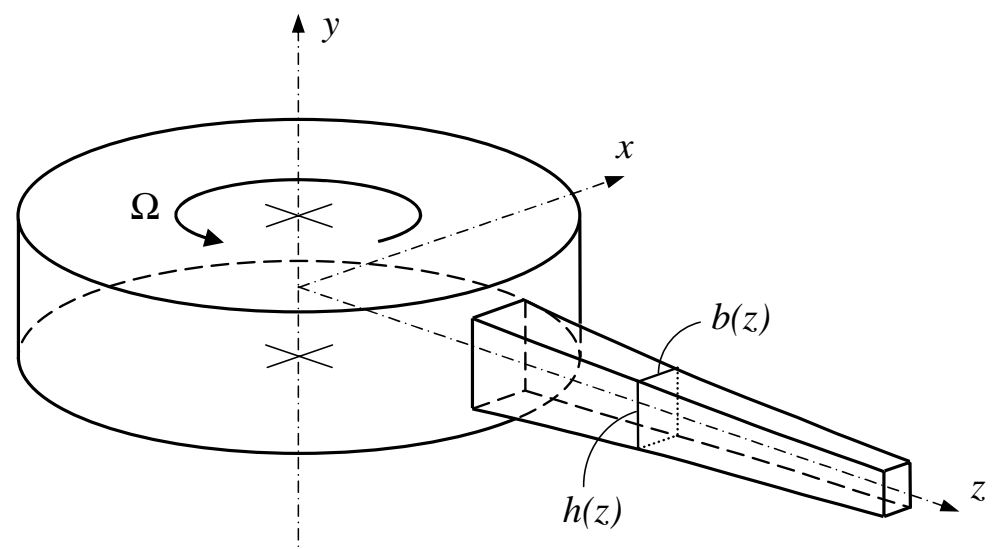

Fig. 1. Rotating tapered beam.

$$
\begin{aligned}
& \frac{d M(z)}{d z}+V(z)=0, \\
& \frac{d V(z)}{d z}=0
\end{aligned}
$$

where

$$
\begin{aligned}
& M(z)=E I(z) \frac{d \theta}{d z} \\
& V(z)=k A(z) G\left(\frac{d v}{d z}-\theta\right)
\end{aligned}
$$

The notation used throughout this paper is listed in the Appendix. Equation (2) gives a constant shear force along the length of the beam. Hence, considering this constant shear force in Eq. (1), bending moment is obtained by integration as

$$
M(z)=C_{1} z+C_{2} .
$$

By substituting Eq. (5) into Eq. (3), and integrating, the cross-sectional rotation is expressed as

$$
\theta(z)=\int \frac{1}{E I(z)}\left(C_{1} z+C_{2}\right) d z
$$

Then, substituting Eq. (6) along with Eqs (3) and (4) into Eq. (1), and integrating yields

$$
v(z)=\int\left\{\theta-\frac{1}{k A(z) G} \frac{d}{d z}\left[E I(z) \frac{d \theta}{d z}\right]\right\} d z
$$

Now, the rotating tapered Timoshenko beam shown in Fig. 1 is considered to indicate the cross-sectional parameters. The breadth and depth of the beam are selected as follows:

$$
\begin{aligned}
& b(z)=b_{c} z^{-m}, \\
& h(z)=h_{c} z^{-n}
\end{aligned}
$$

where $b_{c}=b_{r} z_{r}^{m}$ and $h_{c}=h_{r} z_{r}^{n}$. Hence, the cross-sectional area of the beam can be written as

$$
A(z)=A_{c} z^{-r}
$$

where $A_{c}=b_{c} h_{c}$ and $r=m+n$.

Also, the area moment of inertia of the cross-section about $x$ axis can be expressed as 


$$
I(z)=I_{x x c} z^{-p}
$$

where $I_{x x c}=b_{c} h_{c}^{3} / 12$ and $p=m+3 n$.

Substituting Eq. (11) into Eq. (6), and integrating yields

$$
\theta(z, t)=\theta_{0}(t)+\theta_{1}(t) z^{p+1}+\theta_{2}(t) z^{p+2}
$$

Also, substituting Eqs (10)-(12) into Eq. (7), and integrating yields

$$
v(z, t)=v_{0}(t)+v_{1}(t) z+v_{2}(t) z^{p+2}+v_{3}(t)\left(z^{p+3}-c_{r} z^{r+1}\right)
$$

where

$$
\begin{aligned}
& v_{1}(t)=\theta_{0}(t), \quad v_{2}(t)=\theta_{1}(t) /(2+p), \quad v_{3}(t)=\theta_{2}(t) /(3+p) \\
& c_{r}=E I_{x x c}(2+p)(3+p) /\left(k G A_{c}(1+r)\right)
\end{aligned}
$$

It is convenient to express the relationships between the coefficients of the cross-sectional rotation and of the transverse displacement in the matrix form:

$$
\left\{c_{\theta}\right\}=[B]\left\{c_{v}\right\}
$$

where

$$
\begin{aligned}
& \left\{c_{\theta}\right\}=\left\{\theta_{0}(t) \theta_{1}(t) \theta_{2}(t)\right\}^{T} \\
& \left\{c_{v}\right\}=\left\{\begin{array}{llll}
v_{0}(t) & v_{1}(t) & v_{2}(t) & v_{3}(t)
\end{array}\right\}^{T} \\
& {[B]=\left[\begin{array}{cccl}
0 & 1 & 0 & 0 \\
0 & 0 & 2+p & 0 \\
0 & 0 & 0 & 3+p
\end{array}\right]}
\end{aligned}
$$

The $[B]$ matrix is termed as polynomial coefficients coupling matrix. On the other hand, the cross-sectional rotation given in Eq. (12) may be written as follows:

$$
\theta(z, t)=\left[P_{\theta}\right]\left\{c_{\theta}\right\}
$$

where

$$
\left[P_{\theta}\right]=\left[\begin{array}{lll}
1 & z^{p+1} & z^{p+2}
\end{array}\right]
$$

Also, the transverse displacement given in Eq. (13) may be expressed as follows:

$$
v(z, t)=\left[P_{v}\right]\left\{c_{v}\right\}
$$

where

$$
\left[P_{v}\right]=\left[\begin{array}{llll}
1 & z & z^{p+2} & \left(z^{p+2}-c_{r} z^{r+1}\right)
\end{array}\right]
$$

Now, the finite element model of a rotating tapered Timoshenko beam shown in Fig. 2 is considered. Nodal freedoms of the new finite element are the transverse displacement and the cross-sectional rotation. Therefore, the element displacement vector is given by

$$
\left\{q_{e}\right\}=\left\{\begin{array}{llll}
v_{I} & \theta_{I} & v_{I I} & \theta_{I I}
\end{array}\right\}^{T}
$$

Then, by using Eqs (12)-(15), the element displacement vector can be expressed in terms of the polynomial coefficient vector of transverse displacement as follows:

$$
\left\{q_{e}\right\}=[C]\left\{c_{v}\right\}
$$

where 


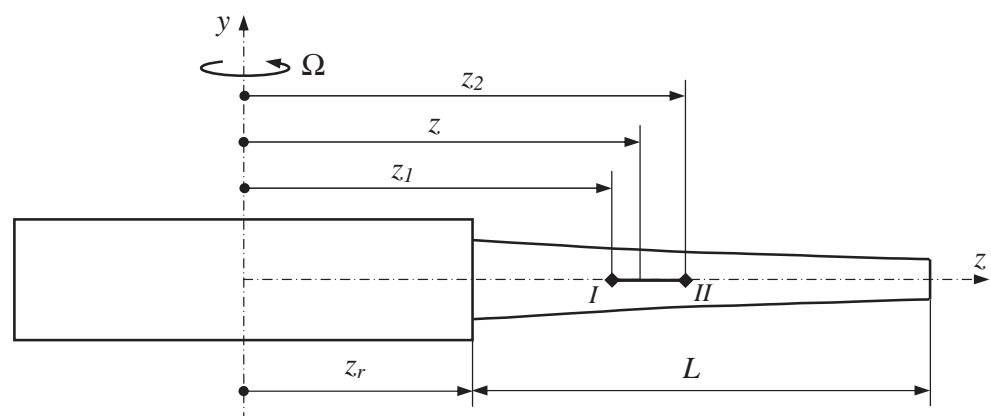

Fig. 2. Finite element model of rotating tapered Timoshenko beam.

$$
[C]=\left[\begin{array}{cccl}
1 & z_{1} & z_{1}^{p+2} & z_{1}^{p+3}-c_{r} z_{1}^{r+1} \\
0 & 1 & (2+p) z_{1}^{p+1} & (3+p) z_{1}^{p+2} \\
1 & z_{2} & z_{2}^{p+2} & z_{2}^{p+3}-c_{r} z_{2}^{r+1} \\
0 & 1 & (2+p) z_{2}^{p+1} & (3+p) z_{2}^{p+2}
\end{array}\right]
$$

in which the matrix $[C]$ is termed as "element displacement-polynomial coefficient matrix". Finally, Eq. (20) can be expressed by using Eqs (16) and (25) as

$$
\theta(z, t)=\left[P_{\theta}\right][B][C]^{-1}\left\{q_{e}\right\}
$$

and also, Eq. (22) can be expressed by using Eq. (25) as

$$
v(z, t)=\left[P_{v}\right][C]^{-1}\left\{q_{e}\right\}
$$

\section{Derivation of the finite element mass and stiffness matrices}

The elastic potential energy of the tapered Timoshenko beam is given in references $[15,16]$ by

$$
U_{e}=0.5 \int_{z_{1}}^{z_{2}} E I(z)\left(\frac{d \theta(z, t)}{d z}\right)^{2} d z+0.5 \int_{z_{1}}^{z_{2}} k G A(z)\left(\frac{d v(z, t)}{d z}-\theta(z, t)\right)^{2} d z
$$

By substituting Eqs (10), (11), (27), and (28) into Eq. (29) gives

$$
U_{e}=0.5\left\{q_{e}\right\}^{T}\left[K_{e}\right]\left\{q_{e}\right\}
$$

where

$$
\left[K_{e}\right]=[C]^{-T}[k][C]^{-1}
$$

in which

$$
\begin{aligned}
{[k]=} & {[B]^{T}\left\{E \int_{z_{1}}^{z_{2}} I(z)\left[P_{\theta}^{\prime}\right]^{T}\left[P_{\theta}^{\prime}\right] d z+k G \int_{z_{1}}^{z_{2}} A(z)\left[P_{\theta}\right]^{T}\left[P_{\theta}\right] d z\right\}[B] } \\
& -k G\left\{[B]^{T} \int_{z_{1}}^{z_{2}} A(z)\left[P_{\theta}\right]^{T}\left[P_{v}^{\prime}\right] d z+\int_{z_{1}}^{z_{2}} A(z)\left[P_{v}^{\prime}\right]^{T}\left[P_{\theta}\right] d z[B]\right\}+k G \int_{z_{1}}^{z_{2}} A(z)\left[P_{v}^{\prime}\right]^{T}\left[P_{v}^{\prime}\right]
\end{aligned}
$$

The symbol ", " used throughout this paper represents differentiation with respect to $z$. The geometric strain energy due to centrifugal force is written as follows [15]:

$$
U_{g}=0.5 \int_{z_{1}}^{z_{2}} P(z)\left(\frac{d v(z, t)}{d z}\right)^{2} d z
$$

where 


$$
P(z)=\int_{z}^{z_{r}+L} \rho A(z) \Omega^{2} z d z
$$

Similarly, by substituting Eq. (34) along with Eqs (10) and (28) into Eq. (33) leads to

$$
U_{g}=0.5\left\{q_{e}\right\}^{T}\left[S_{e}\right]\left\{q_{e}\right\}
$$

where

$$
\left[S_{e}\right]=[C]^{-T}[s][C]^{-1}
$$

in which

$$
[s]=\int_{z_{1}}^{z_{2}} P(z)\left[P_{v}^{\prime}\right]^{T}\left[P_{v}^{\prime}\right] d z
$$

Finally, the kinetic energy of the tapered Timoshenko beam is expressed as follows [15,16]:

$$
T=0.5 \int_{z_{1}}^{z_{2}} \rho A(z)\left(\frac{d v(z, t)}{d t}\right)^{2} d z+0.5 \int_{z_{1}}^{z_{2}} \rho I(z)\left(\frac{d \theta(z, t)}{d t}\right)^{2} d z
$$

Similarly, by substituting Eqs (10), (11), (27), and (28) into Eq. (38) yields

$$
T=0.5\left\{\dot{q}_{e}\right\}^{T}\left[M_{e}\right]\left\{\dot{q}_{e}\right\}
$$

where the overdot is the compact notation for differentiation with respect to time, and $\left[M_{e}\right]$ is

$$
\left[M_{e}\right]=[C]^{-T}[m][C]^{-1}
$$

in which

$$
[m]=\rho\left\{\int_{z_{1}}^{z_{2}} A(z)\left[P_{v}\right]^{T}\left[P_{v}\right] d z+[B]^{T} \int_{z_{1}}^{z_{2}} I(z)\left[P_{\theta}\right]^{T}\left[P_{\theta}\right] d z[B]\right\}
$$

\section{Dynamic equilibrium equation and Solution technique}

In order to obtain the natural frequencies for out-of-plane vibration of non-rotating/rotating uniform and tapered Timoshenko beams, the dynamic equilibrium equation is reduced to eigenvalue problem given below,

$$
\left(([K]+[S])-\omega^{2}[M]\right)\{q\}=0
$$

Element elastic stiffness, geometric stiffness, and mass matrices given in Eqs (31), (36), and (40), respectively, are used directly in the semi-symbolic computer program developed in MATLAB ${ }^{\circledR}$ for this study. To form the global matrices, calculated element matrices are assembled in the usual way, and then boundary conditions are applied as clamped at $z_{r}$-free. The eigenvalue problem given in Eq. (42) is then solved.

\section{Numerical results and discussion}

The accuracy, efficiency, and versatility of the new finite element model are verified by the several examples of the Timoshenko beam vibration problem. The first group of examples to be considered is the case of free vibration of non-rotating uniform Timoshenko beams. Solutions of the aforementioned problem by using a proper number of elements are obtained to demonstrate the convergence pattern, compared with the exact results found from the frequency equation given by Huang [7], and Huang and Kung [8], and then presented in Tables 1 and 2 for $r_{g} / L=0.05$ and $r_{g} / L=0.1$, respectively. The present finite element solutions with 14 elements for $r_{g} / L=$ 0.05 and 16 elements for $r_{g} / L=0.1$ are converged to the exact solutions for the fourth frequency parameters with less than $1 \%$ error $(\%$ Error $=100 *[$ Present/Exact-1] $)$. Furthermore, $\%$ errors of the present solutions for the first frequency parameters given in Tables 1 and 2 are extremely small. 
Table 1

Convergence pattern and comparison of frequency parameters for uniform Timoshenko beam $\left(r_{g} / L=0.05, z_{r} / L=3, E / G=2.6, k=0.85\right)$

\begin{tabular}{lcrrr}
\hline Frequency parameters $\lambda$ & First & Second & Third & Fourth \\
\hline Present $N=4$ & 3.437327 & 19.278897 & 48.565736 & 85.450496 \\
Present $N=6$ & 3.436809 & 19.200096 & 47.597646 & 83.123418 \\
Present $N=8$ & 3.436640 & 19.173099 & 47.229024 & 81.490162 \\
Present $N=10$ & 3.436565 & 19.160758 & 47.056972 & 80.690445 \\
Present $N=12$ & 3.436524 & 19.154101 & 46.963417 & 80.249698 \\
Present $N=14$ & 3.436500 & 19.150103 & 46.907017 & 79.982505 \\
Present $N=16$ & 3.436484 & 19.147516 & 46.870425 & 79.808657 \\
Exact $[7,8]$ & 3.436434 & 19.139101 & 46.751022 & 79.239252 \\
$\%$ Error for $N=14$ & 0.001920 & 0.057486 & 0.333672 & 0.937986 \\
\hline
\end{tabular}

Table 2

Convergence pattern and comparison of frequency parameters for uniform Timoshenko beam $\left(r_{g} / L=0.1, z_{r} / L=3, E / G=2.6, k=0.85\right)$

\begin{tabular}{lcrrr}
\hline Frequency parameters $\lambda$ & First & Second & Third & \multicolumn{1}{c}{ Fourth } \\
\hline Present $N=4$ & 3.233589 & 14.745679 & 33.709784 & 53.748206 \\
Present $N=6$ & 3.232099 & 14.628146 & 32.641472 & 51.237414 \\
Present $N=8$ & 3.231583 & 14.585885 & 32.224311 & 49.982820 \\
Present $N=10$ & 3.231346 & 14.566170 & 32.026774 & 49.365712 \\
Present $N=12$ & 3.231217 & 14.555424 & 31.918554 & 49.022962 \\
Present $N=14$ & 3.231139 & 14.548933 & 31.853031 & 48.814069 \\
Present $N=16$ & 3.231089 & 14.544715 & 31.810404 & 48.677670 \\
Exact $[7,8]$ & 3.230925 & 14.530913 & 31.670669 & 48.228066 \\
\% Error for $N=16$ & 0.005077 & 0.094984 & 0.441213 & 0.932246 \\
\hline
\end{tabular}

Table 3

Comparison of frequency parameters for rotating uniform Timoshenko beam $\left(r_{g} / L=0.05, z_{r} / L=3, E / G=2.6, k=0.85, \eta=10\right)$

\begin{tabular}{lcccc}
\hline Frequency parameters $\lambda$ & First & Second & Third & Fourth \\
\hline Present $N=16$ & 23.524 & 56.105 & 97.188 & 144.490 \\
Wang et al. [21] & 23.514 & 56.072 & 97.011 & 143.815 \\
Yokoyama [22] $N=16$ & 23.524 & 56.105 & 97.188 & 144.490 \\
Lee and Lin [13] & 23.491 & 55.984 & 96.913 & 143.710 \\
\hline
\end{tabular}

Table 4

Comparison of frequency parameters for rotating uniform Timoshenko beam $\left(r_{g} / L=0.1, z_{r} / L=3, E / G=2.6, k=0.85, \eta=\right.$ 10)

\begin{tabular}{lcccc}
\hline Frequency parameters $\lambda$ & First & Second & Third & Fourth \\
\hline Present $N=16$ & 23.050 & 45.598 & 67.716 & 73.076 \\
Wang et al. [21] & 23.037 & 45.428 & 66.854 & 72.313 \\
Yokoyama [22] $N=16$ & 23.050 & 45.598 & 67.716 & 73.076 \\
Lee and Lin [13] & 22.938 & 44.781 & 66.287 & 71.967 \\
\hline
\end{tabular}

The second group of examples deals with the out-of-plane vibration of the rotating uniform Timoshenko beams. In Tables 3 and 4, the present frequency parameters of rotating Timoshenko beams obtained by using 16 elements are compared with the results given by Wang et al. [21], Yokoyama [22], and Lee and Lin [13]. Among these studies, while Wang et al. [21] used the extended Galerkin's method, Lee and Lin [13] utilized the power series method.

The last group of examples is employed to evaluate the present finite element models for the cases of non-rotating and rotating tapered Timoshenko beams. The two tapered beam models based on the physical and geometrical parameters given in Table 5 and 6 are considered. The out-of-plane natural frequencies of these beams are found from the present finite element models by using 16 elements and from the solid finite element models created in ABAQUS by using 390 hexahedral elements for reasonable rotational speeds based on the normal stress due to the centrifugal force. The out-of-plane frequency parameters for rotating tapered Timoshenko beams obtained from the 
Table 5

Comparison of frequency parameters for non-rotating/rotating tapered Timoshenko beam $\left(r_{g} / L=0.05, z_{r} / L=1, E / G=2.6, k=\right.$ $0.85, m=n=1$ )

\begin{tabular}{lcccc}
\hline & Rotatinal speed & \multicolumn{3}{c}{ Frequency parameters $\lambda$} \\
\cline { 3 - 5 } & parameter $\eta$ & First & Second & Third \\
\hline Present $N=16$ & 0 & 4.158 & 16.688 & 38.315 \\
ABAQUS & 0 & 4.161 & 16.712 & 38.333 \\
Present $N=16$ & 0.5 & 4.250 & 16.778 & 38.408 \\
ABAQUS & 0.5 & 4.248 & 16.787 & 38.395 \\
Present $N=16$ & 1 & 4.513 & 17.045 & 38.687 \\
ABAQUS & 1 & 4.500 & 17.010 & 38.583 \\
\hline
\end{tabular}

Table 6

Comparison of frequency parameters for non-rotating/rotating tapered Timoshenko beam $\left(r_{g} / L=0.1, z_{r} / L=1, E / G=2.6, k=\right.$ $0.85, m=n=1$ )

\begin{tabular}{lcccc}
\hline & Rotatinal speed & \multicolumn{3}{c}{ Frequency parameters $\lambda$} \\
\cline { 3 - 5 } & parameter $\eta$ & First & Second & Third \\
\hline Present $N=16$ & 0 & 3.955 & 14.013 & 28.863 \\
ABAQUS & 0 & 3.989 & 14.139 & 28.936 \\
Present $N=16$ & 0.5 & 4.048 & 14.111 & 28.980 \\
ABAQUS & 0.5 & 4.065 & 14.192 & 38.971 \\
Present $N=16$ & 1 & 4.312 & 14.402 & 29.327 \\
ABAQUS & 1 & 4.284 & 14.349 & 29.085 \\
\hline
\end{tabular}

present finite element models and those produced by ABAQUS are compared in Tabls 5 and 6 . It is evident that the results presented in Table 5 and 6 are very consistent.

\section{Conclusion}

A finite element model based on the coupled displacement field has been developed for the vibration analysis of rotating tapered Timoshenko beams. Moreover, the taper functions of breadth and depth of the cross-section of the beam have been taken into account in derivation of the displacement functions of the finite element model for the first time. The convergency, accuracy, efficiency, and versatility of the new model have been examined for the possible cases. The convergence of the present model results is very rapid. Furthermore, the present results are in excellent agreement with the exact results found by using frequency equation for uniform beams, with the results available in the literature found by extended Galerkin's method, finite element method, and power series expansion for rotating uniform beams, and finally with the results produced by ABAQUS for the general case.

\section{References}

[1] A. Bazoune and Y.A. Khulief, A finite beam element for vibration analysis of rotating tapered Timoshenko beams, Journal of Sound and Vibration 156(1) (1992), 141-164.

[2] S.-T. Choi and Y.-T. Chou, Vibration analysis of elastically supported turbomachinery blades by the modified differential quadrature method, Journal of Sound and Vibration 240(5) (2001), 937-953.

[3] W.L. Cleghorn and B. Tabarrok, Finite element formulation of a tapered Timoshenko Beam for free lateral vibration analysis, Journal of Sound and Vibration 152(3) (1992), 461-470.

[4] R. Davis, R.D. Henshell and G.B. Warburton, A Timoshenko beam element, Journal of Sound and Vibration 22(4) (1972), 475-487.

[5] D.J. Dawe, A finite element for the vibration analysis of Timoshenko beams, Journal of Sound and Vibration 60(1) (1978), 11-20.

[6] B. Downs, Transverse vibrations of cantilever beams having unequal breadth and depth tapers, Journal of Applied Mechanics ASME $\mathbf{4 4}$ (1977), 737-742

[7] T.C. Huang, The effect of rotatory inertia and of shear deformation on the frequency and normal mode equations of uniform beams with simple end conditions, Journal of Applied Mechanics ASME 28 (1961), 579-584.

[8] T.C. Huang and C.S. Kung, New tables of eigenfunctions representing normal modes of vibration of Timoshenko beams, Developments in Theoretical and Applied Mechanics 1 (1963), 59-71. 
[9] D.J. Inman, Engineering Vibration, (Second edition), Prentice-Hall, New Jersey, 2001.

[10] T. Irie, G. Yamada and I. Takahashi, Determination of the steady state response of a Timoshenko beam of varying cross-section by use of the spline interpolation technique, Journal of Sound and Vibration 63(2) (1979), 287-295.

[11] T. Irie, G. Yamada and I. Takahashi, Vibration and stability of a non-uniform Timoshenko beam subjected to a follower force, Journal of Sound and Vibration 70(4) (1980), 503-512.

[12] S.Y. Lee and S.M. Lin, Exact vibration Solutions for nonuniform Timoshenko beams with attachments, AIAA Journal 30(12) (1992), 2930-2934.

[13] S.Y. Lee and S.M. Lin, Bending vibrations of rotating nonuniform Timoshenko beams with an elastically restrained root, Journal of Applied Mechanics ASME 61 (1994), 949-955.

[14] S. Mulmule, G. Singh and G. Venkateswara Rao, Flexural vibration of rotating tapered Timoshenko beams, Journal of Sound and Vibration 160(2) (1993), 372-377.

[15] L. Meirovitch, Analytical Methods in Vibrations, Macmillan, New York, 1967.

[16] M. Petyt, Introduction to Finite Element Vibration Analysis, Cambridge University Press, Cambridge, 1990.

[17] J.S. Przemieniecki, Theory of Matrix Structural Analysis, McGraw-Hill, New York, 1968.

[18] S.S. Rao and R.S. Gupta, Finite element vibration analysis of rotating Timoshenko beams, Journal of Sound and Vibration 242(1) (2001), $103-124$.

[19] D.L. Thomas, J.M. Wilson and R.R. Wilson, Timoshenko beam finite elements, Journal of Sound and Vibration 31(3) (1973), 315-330.

[20] C.W.S. To, A linearly tapered beam finite element incorporating shear deformation and rotary inertia for vibration analysis, Journal of Sound and Vibration 78(4) (1981), 475-484.

[21] J.T.S. Wang, O. Mahrenholtz and J. Bohm, Extended Galerkin's method for rotating beam vibrations using Legendre Polynomials, Solid Mechanics Archives 1 (1976), 341-365.

[22] T. Yokoyama, Free vibration characteristics of rotating Timoshenko beams, International Journal of Mechanical Sciences, 30(10) (1988), $743-755$.

\section{Appendix: Notation}

$A(z) \quad$ cross-sectional area of the beam

$A_{c} \quad$ coefficient for cross-sectional area of the beam

$A_{r} \quad=b_{r} h_{r}$, root cross sectional area of the beam

$b(z) \quad$ breadth of the beam at co-ordinate $z$

$b_{c} \quad$ coefficient for breadth of the beam

$b_{r} \quad$ breadth of the beam at co-ordinate $z_{r}$

$[B] \quad$ polynomial coefficients coupling matrix

$c_{r} \quad$ coefficient defined in Eq. (15)

$\left\{c_{v}\right\} \quad$ polynomial coefficient vector of transverse displacement

$\left\{c_{\theta}\right\} \quad$ polynomial coefficient vector of cross-sectional rotation

$[C] \quad$ element displacement-polynomial coefficient matrix

$C_{1}, C_{2}$ constants of integration

$E, G \quad$ elastic modulus and shear modulus, respectively

$h(z) \quad$ depth of the beam at co-ordinate $z$

$h_{c} \quad$ coefficient for depth of the beam

$h_{r} \quad$ depth of the beam at co-ordinate $z_{r}$

$I(z) \quad$ area moments of inertia of the cross-section about $x$ axis at co-ordinate $z$

$I_{x x c}$ coefficient for area moments of inertia of the cross-section about $x$ axis

$I_{x x r}$ $=b_{r} h_{r}^{3} / 12$, area moment of inertia of the cross section at root of the beam

$[k] \quad$ matrix given by Eq. (32)

$[K] \quad$ global elastic stiffness matrix

$\left[K_{e}\right] \quad$ element elastic stiffness matrix

$L \quad$ length of the beam

$m \quad$ breadth taper parameter

$M(z) \quad$ bending moment about $x$ axis at co-ordinate $z$

$[m] \quad$ matrix given by Eq. (41)

$[M] \quad$ global mass matrix

$\left[M_{e}\right] \quad$ element mass matrix 


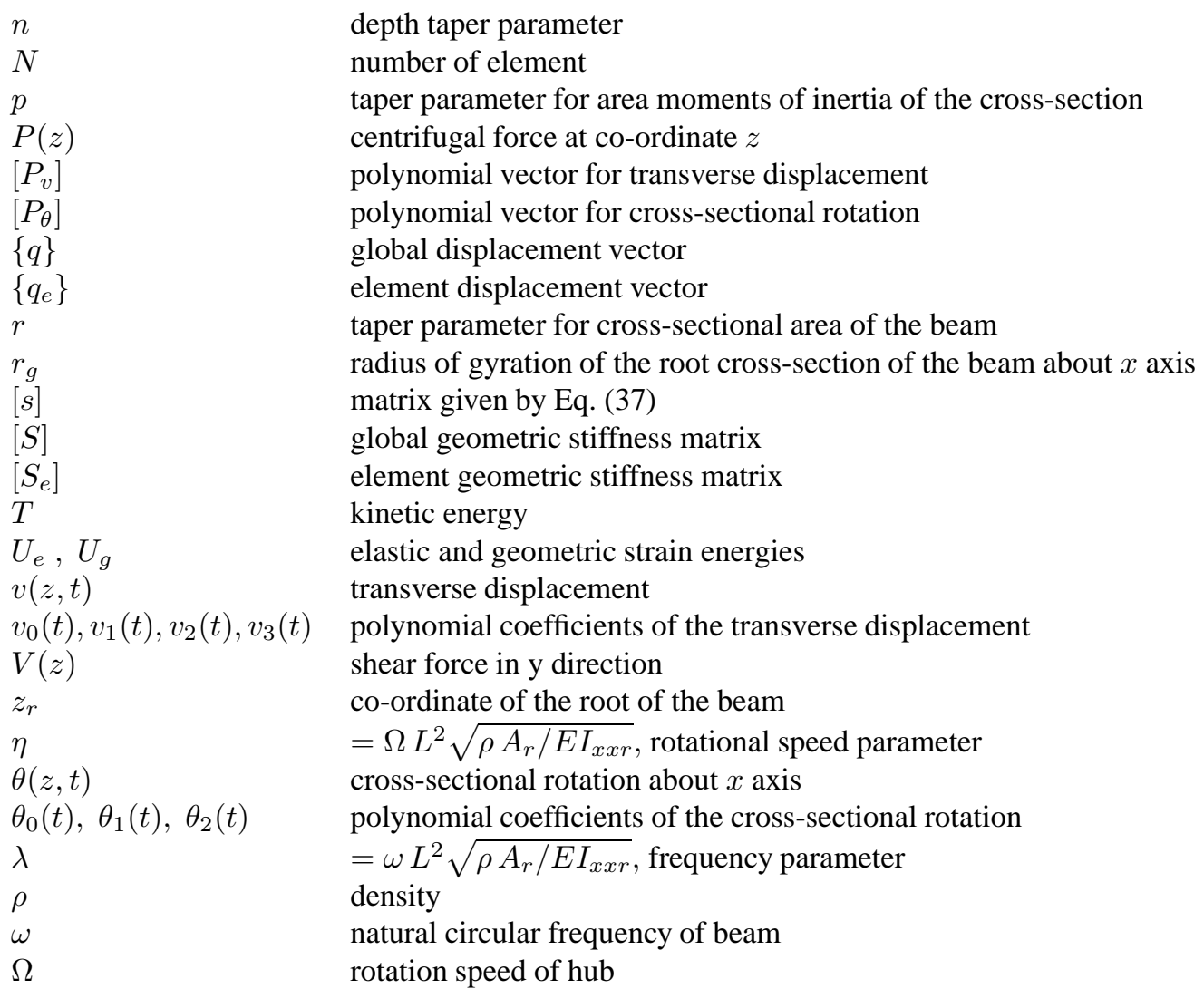



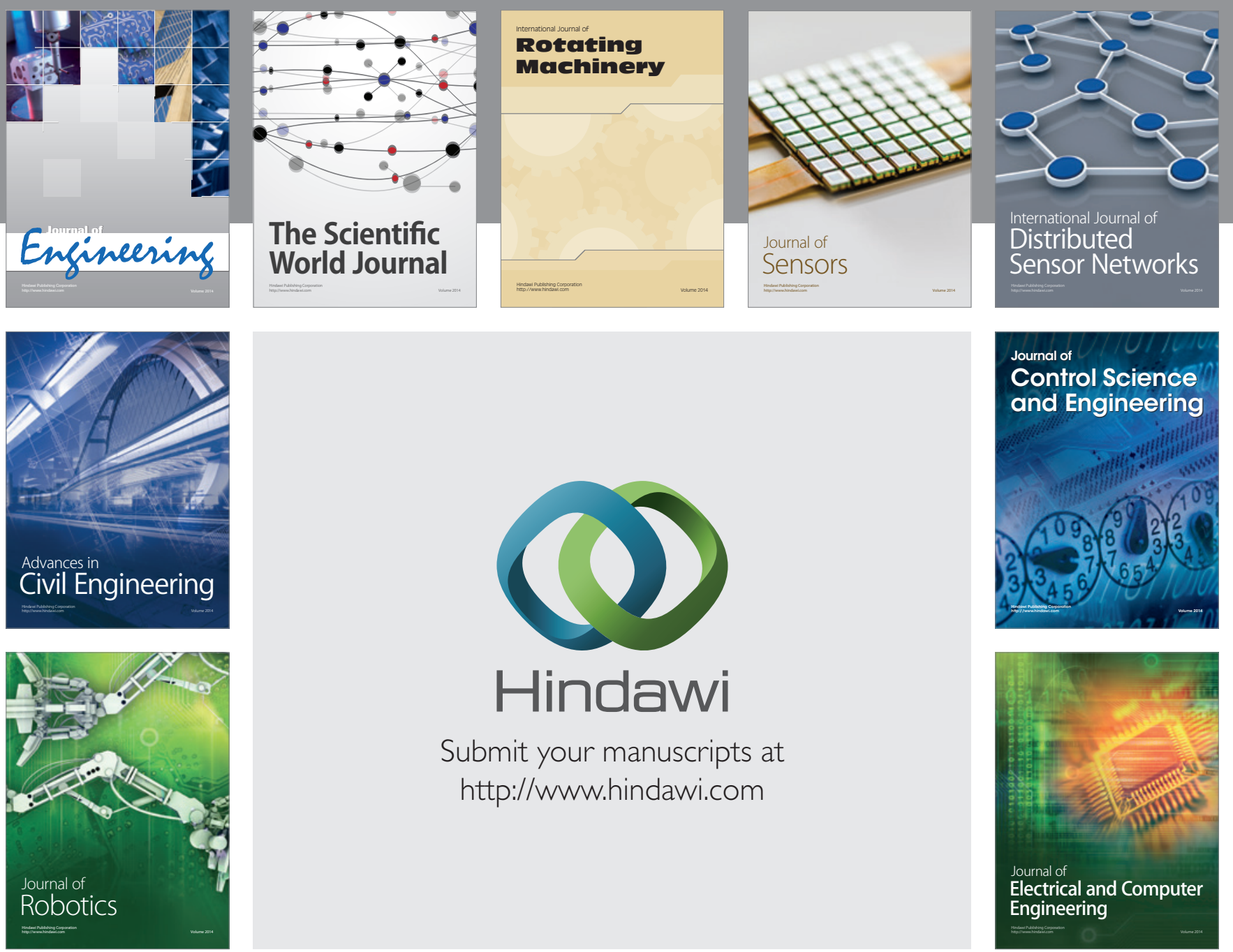

Submit your manuscripts at

http://www.hindawi.com
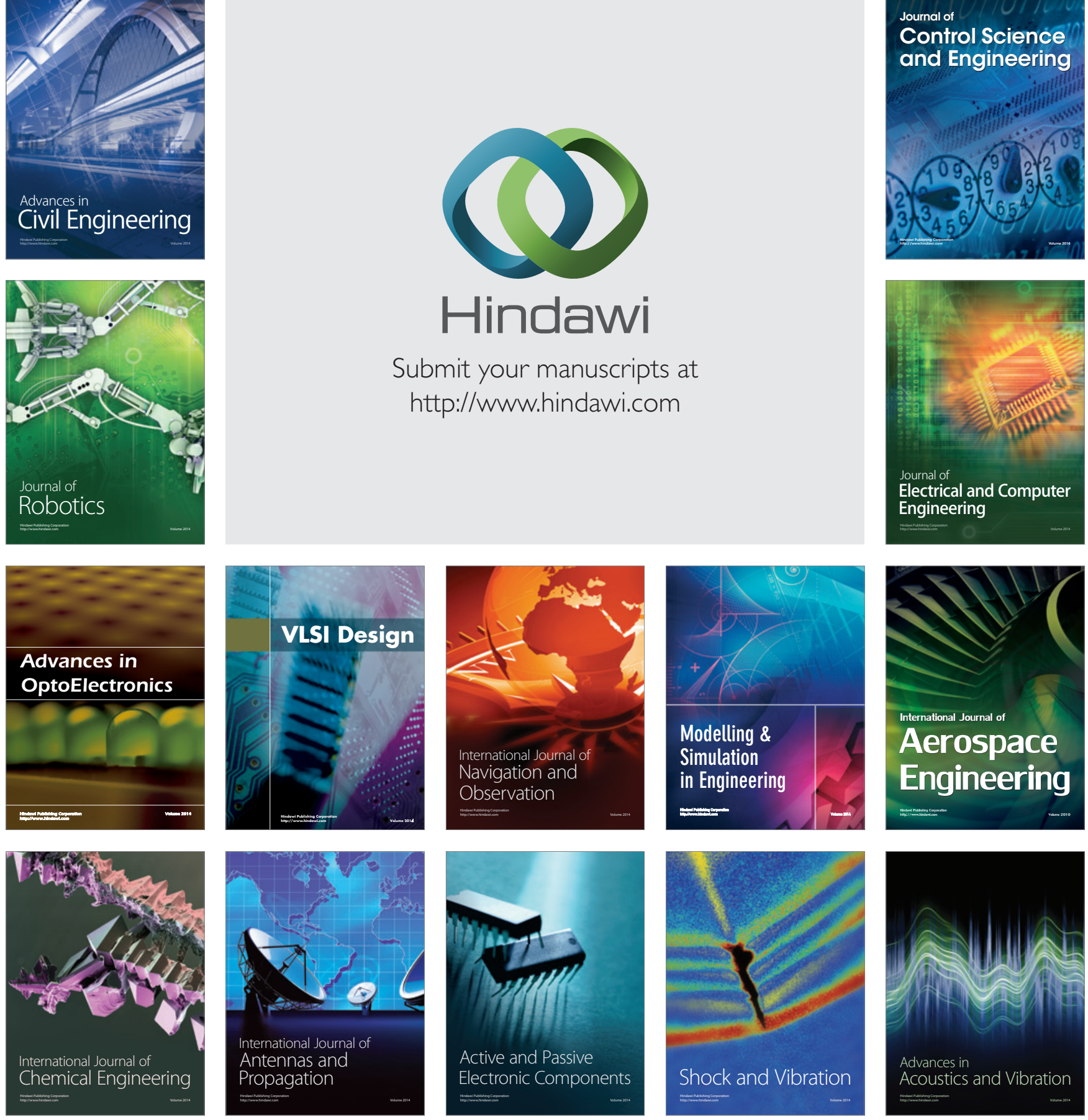